\title{
Risk factors for mortality or delisting of patients from the pediatric heart transplant waiting list
}

\author{
Aamir Jeewa, MD, Cedric Manlhiot, BS, Paul F. Kantor, MBBCh, Seema Mital, MD, \\ Brian W. McCrindle, MD, MPH, and Anne I. Dipchand, MD
}

Objective: Current literature assessing factors associated with outcomes of patients waiting for pediatric heart
transplants has focused on survival to transplant and mortality. Our aim was to determine risk factors associated
with the outcomes of delisting, transplant, or death while waiting.

\begin{abstract}
Methods: In this single-center, retrospective study of patients listed for heart transplants, competing risk analysis was used to model survival from listing to 4 competing outcomes (transplant, death, delisting for clinical deterioration, delisting for clinical improvement or surgical intervention).
\end{abstract}

Results: There were 308 listing episodes in 280 patients. In competing risk analysis, $11 \%$ remained listed at 6 months (transplant $62 \%$, dead 13\%, delisted worse 6\%, delisted improved 8\%). Extracorporeal membrane oxygenation and ventricular assist devices were associated both with higher probability of transplant (hazard ratio [HR], 2.8; $P<.001)$ and delisting for clinical deterioration $(\mathrm{HR}, 2.7 ; P=.06)$. Younger age at listing and complex congenital heart disease were shared risk factors for mortality (HR, 1.07; $P=.05$; HR, 2.9; $P=.003)$ and delisting because of clinical deterioration (HR, 1.17; $P=.01 ; \mathrm{HR}, 2.8 ; P=.02)$. Younger age at listing and fetal listing were associated with delisting for clinical improvement or surgical intervention (HR, 1.13; $P=.01 ; \mathrm{HR}, 2.9 ; P=.02)$.

Conclusions: Overall survival to transplant depends on risk factors including age at listing, cardiac diagnosis, and mechanical circulatory support. Knowledge of risk factors for death and delisting for clinical deterioration or improvement can assist patient selection and timing of transplant listing. (J Thorac Cardiovasc Surg 2014;147:462-8)

Pediatric patients waiting for heart transplants have the highest waiting list mortality relative to all other solid organ transplant groups. ${ }^{1-4}$ Many factors affect how long a patient is expected to wait for a transplant such as weight, blood group, age, underlying diagnosis, and HLA sensitization. ${ }^{2,5,6}$ Organ allocation algorithms aim to stratify patients by risk factors for death to optimize organ allocation and reduce waiting list mortality. Recent studies, however, highlight that the current systems may be imperfect and point out that there is a need for ongoing review of the existing algorithms with a clear view to achieving optimal patient outcomes during the wait for transplant. ${ }^{7,8}$ Currently, the Canadian organ allocation system (COAS) for pediatric heart transplantation stratifies patients according to level of medical urgency, with further definitions for each level

From the Labatt Family Heart Centre, Hospital for Sick Children, Toronto, Ontario, Canada.

Disclosures: Authors have nothing to disclose with regard to commercial support. Received for publication Nov 8, 2012; revisions received Aug 12, 2013; accepted for publication Sept 8, 2013; available ahead of print Nov 4, 2013.

Address for reprints: Aamir Jeewa, MD, Baylor College of Medicine, Heart Failure and Transplant Program, Texas Children's Hospital, 6621 Fannin, 19th floor West Tower, Houston, TX 77030 (E-mail: jeewa@bcm.edu).

0022-5223/\$36.00

Copyright (C) 2014 by The American Association for Thoracic Surgery

http://dx.doi.org/10.1016/j.jtcvs.2013.09.018 of "critical illness" comparable to the one in use by the United Network for Organ Sharing (UNOS; Table 1). Thus a patient that who is receiving mechanical ventilation and mechanical circulatory support (MCS) will have a higher waiting list status than that of a patient receiving high-dose inotropes alone, regardless of time spent on the waiting list.

Almond and colleagues ${ }^{8}$ reported waiting list mortality in the United States according to data from the Scientific Registry of Transplant Recipients (SRTR). Overall waiting list mortality was $17 \%$, but more importantly there was considerable heterogeneity within the highest medical urgency category, status $1 \mathrm{~A}$, which comprised $60 \%$ of the listings. Status $1 \mathrm{~A}$ patients had a waiting list mortality that ranged from $5 \%$ to $39 \%$, depending on their level of hemodynamic support. This study concluded that, despite improvements in the organ allocation system since 1999, pediatric waiting list mortality continues to remain unacceptably high, and the current organ allocation system in the United States remains suboptimal for characterizing medical urgency. ${ }^{8}$

Previous studies assessing factors associated with waiting list outcomes have mainly focused on survival to transplant and mortality. ${ }^{2,4,6,9-13}$ Of equal importance, however, are factors associated with removal from the waiting list, or "delisting," whether for clinical 

Abbreviations and Acronyms
ABO-I = ABO incompatible
$\mathrm{CAV}=$ cardiac allograft vasculopathy
CHD = congenital heart disease
COAS $=$ Canadian organ allocation system
$\mathrm{ECMO}=$ extracorporeal membrane oxygenation
HLHS $=$ hypoplastic left heart syndrome
MCS = mechanical circulatory support
SRTR $=$ Scientific Registry of Transplant Recipients
UNOS $=$ United Network for Organ Sharing

deterioration or for clinical improvement, surgical intervention, or both. These expansions on the conventional risk factor analyses for delisting may help with decision making related to heart transplant eligibility and timing of listing, and they may contribute to optimal risk stratification within organ allocation algorithms.

The purpose of this study was to assess our institution's waiting list mortality within the current COAS and the associated risk factors for delisting because of clinical deterioration or delisting because of clinical improvement or surgical intervention.

\section{MATERIALS AND METHODS}

This was a retrospective study of all patients listed for heart transplants for congenital or acquired heart disease at The Hospital for Sick Children, Toronto, Ontario, Canada, between 1990 and 2008. Research ethics board approval was obtained,. Detailed medical history was reviewed, including cardiac diagnosis, medical condition leading to the transplant, blood group, requirement for MCS, fetal listing, and waiting list outcomes. Status at the time of listing was according to the COAS. Table 1 outlines the comparison between the COAS and that of UNOS.

Data are described as means with SD, medians with minimum and maximum values, and frequencies as appropriate. A competing risks analysis was performed to characterize outcomes after pediatric patients were listed for heart transplants. The competing risk analysis estimates, at each time point after listing, the likelihood of each competing event occurring against all others, according to a parametric survival model for each event. To create the competing risks, parametric survival models were created for each of the following competing outcomes: (1) heart transplant, (2) death on the transplant list, (3) delisting because of clinical deterioration or loss of transplant candidacy, and (4) delisting because of clinical improvement or other surgical intervention. Factors associated with each of these outcomes were sought from demographic and clinical characteristics in univariate models and excluded patient status at listing, which was considered a surrogate marker of likelihood of outcomes. Factors with associations at the level of $P<.10$ were included in multivariable models with backward selection to obtain a final model. All statistical analyses were performed with SAS Statistical Software version 9.2 (SAS Institute Inc, Cary NC).

\section{RESULTS}

\section{Patient Population}

There were 308 listing episodes for heart transplants among 280 pediatric patients, $45 \%$ of whom were male, with a median age at listing of 1.6 years (ranging from fetal listing to 17.9 years). A total of 121 patients $(39 \%)$ were eligible and listed for ABO-incompatible (ABO-I) heart transplants. There was a slight predominance of patients with congenital heart disease (CHD) listed for their first heart transplant (58\%), and approximately a third of those had undergone a previous surgical procedure $(37 \%)$. There was the expected predominance of patients belonging to blood group O (49\%). Detailed characteristics of the study population can be found in Table 2.

\section{Overall Outcomes After Listing for Transplant}

For the entire cohort, $70 \%$ patient listings $(\mathrm{n}=216)$ eventually resulted in transplants, $13 \%$ of patients $(\mathrm{n}=40)$ died while on the waiting list, $7 \%(\mathrm{n}=21)$ were delisted because of clinical worsening, $9 \%(n=29)$ were delisted because of clinical improvement or other surgical intervention, and $1 \%(\mathrm{n}=2)$ had yet to reach an outcome at the 2-year mark (Figure 1). Median time from listing to reaching an outcome was 29 days (1-930 days). Despite a low overall waiting list mortality of $13 \%$, the range according to the underlying diagnosis or level of support was quite variable. Factors associated with the highest percentage waiting list mortality while waiting in our cohort were being relisted for primary graft failure $(30 \%)$, Canadian transplant status $4(23 \%)$, extracorporeal membrane oxygenation (ECMO) support $(21 \%)$, age younger than 1 month (18\%), and complex CHD other than hypoplastic left heart syndrome (HLHS; $16 \%$ ).

Patients who were listed status 4 , the highest status according to the COAS, had the shortest time to an outcome (death, transplant, or delisting) relative to status 1 patients (median 10 days vs 64 days; $P<.001$ ) but the lowest transplant rate $(52 \%$ vs $83 \%, P<.001)$. Status 4 at the time of listing was also associated with younger age at listing $(P=.04)$, listing eligible for an ABO-I transplant $(P=.01)$, use of ventricular assist device (VAD) or ECMO $(P<.001)$, diagnoses other than restrictive cardiomyopathy $(P=.004)$ or cardiac allograft vasculopathy $(\mathrm{CAV})(P=.04)$, and primary graft failure $(P<.001)$.

\section{Risk Factor Analysis}

Multivariate analysis indicated that patients with blood group A possessed an expected competitive edge, with a significantly higher likelihood of surviving to transplant (hazard ratio [HR] 2.1 vs all other blood groups; $P<.001)$, whereas those with blood group $\mathrm{O}$ were significantly less likely to survive to transplant (HR, 0.5 ; $P<.001)$. Differences between blood groups were negated in young patients listed for ABO-I transplant, resulting in a higher likelihood of successfully surviving to transplant (HR, 1.4; $P=.03)$. Younger age at listing ( $<1$ month) was associated with increased likelihood of death on the 
TABLE 1. United Network for Organ Sharing and Canadian organ allocation system conversion

\begin{tabular}{lc}
\hline Canadian & Criteria \\
\hline 4 & VAD or Berlin Heart (infants); mechanically ventilated on high- \\
dose single or multiple inotropes with or without mechanical \\
circulatory support; patients should be recertified every $7 \mathrm{~d}$ as \\
status 4 by a qualified physician if still medically appropriate \\
\\
\\
\\
$3.5 \quad$ Infant $<6$ mo; CHD and PGE dependent; high-dose or multiple \\
inotropes in hospital and not candidate for VAD therapy; high \\
PRA ( $>80 \%$ or elevated with 3 previous positive \\
crossmatches); acute ventricular arrhythmias \\
Inotropic support not meeting previously stated criteria; VAD \\
not meeting status 4 criteria; heart-lung transplant candidates \\
Infant $<6$ mo with CHD; cyanotic CHD with resting saturation \\
$<65 \%$; CHD that is arterial shunt dependent; inpatient CPAP \\
or BIPAP support \\
Growth failure ( $<5$ th percentile for weight or height or loss of \\
1.5 SD of expected growth)
\end{tabular}

Home CPAP or BIPAP; hospital management for CHF not meeting previously stated criteria; $\mathrm{CHD}$ with resting saturation $65 \%-75 \%$ or prolonged desaturation to $<60 \%$ with activity; Fontan palliation with PLE; MOT recipient

$1 \quad$ All other out-of-hospital patients; in utero listing

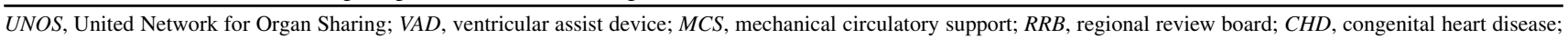
$P G E$, prostaglandin E; $P R A$, panel reactive antibodies; $A H D$, acquired heart disease; $P H T N$, pulmonary hypertension; $C P A P$, continuous positive airway pressure; $B I P A P$, bilevel positive airway pressure; $C H F$, congestive heart failure; $P L E$, protein losing enteropathy; $M O T$, multiorgan transplant; $S D$, standard deviation.

waiting list (HR, 1.07/y; $P=.05)$, delisting because of clinical deterioration (HR, $1.17 / \mathrm{y} ; P=.01$ ), or delisting because of clinical improvement or surgical intervention (HR, 1.13/y; $P=.01$; HR, 2.9 for fetal listing; $P=.02$ ). Patients who were relisted because of primary graft failure were more likely to die waiting (HR, $9.7 ; P=.001)$, as were patients with complex CHD (HR, 2.9; $P=.003)$, who were also more likely to be delisted because of clinical worsening (HR, 2.8; $P=.02$ ). Patients relisted for CAV had a high likelihood of surviving to transplant ( $92 \%$ by 1 year) but had the longest wait time (median 159 days; 4-858 days) versus primary graft failure (median 7 days; 2-40 days; $P<.001$ ). Patients without previous surgical interventions or palliations were at higher risk of dying on the list (HR, 3.6; $P=.004$ ), whereas those requiring MCS, either VAD or ECMO, were more likely to be delisted because of clinical deterioration (HR, 2.7; $P=.06$; Table 3).

\section{Delisting for Clinical Worsening or Loss of Transplant Candidacy}

With respect to patients that were initially listed as status $4,15 \%$ were delisted because of clinical deterioration by

\section{UNOS Criteria}

1A Requires assistance with a ventilator; requires assistance with MCS or balloon pump; candidate who does not meet other status $1 \mathrm{~A}$ criteria may be listed as status $1 \mathrm{~A}$ if the candidate has a life expectancy without a heart transplant of $<14 \mathrm{~d}$, such as for refractory arrhythmia; qualification for status $1 \mathrm{~A}$ under this criterion is valid for $14 \mathrm{~d}$ and may be recertified by an attending physician for 1 additional 14-d period; any further extension of the status $1 \mathrm{~A}$ listing requires a conference with the RRB

Infant $<6$ mo with $\mathrm{CHD}$ or AHD exhibiting reactive PHTN at $>50 \%$ of systemic level; such a candidate may be treated with PGE infusion; requires infusion of high-dose or multiple inotropes

Candidate who does not meet previously stated criteria may be listed as status $1 \mathrm{~A}$ if candidate has a life expectancy $<14 \mathrm{~d}$

1B Requires infusion of low-dose single inotrope; infant $<6$ mo and does not meet status $1 \mathrm{~A}$ criteria

Growth failure $(<5$ th percentile for weight or height, or loss of 1.5 SD of expected growth (height or weight); candidate who does not meet criteria for status $1 \mathrm{~B}$ may be nevertheless assigned to such status on application by transplant physician(s) and justification to the applicable RRB

2 Candidate that does not meet criteria for status $1 \mathrm{~A}$ or $1 \mathrm{~B}$ is listed as status 2
6 months. For patients whose status progressed from an initial listing of status 1,2 , or 3 to a higher status while waiting $(\mathrm{n}=39)$, none were delisted because of clinical deterioration at any point during follow-up. Blood groups $\mathrm{O}$ and $\mathrm{A}$ had similar numbers of patients who were delisted because of clinical deterioration ( $6 \%$ vs $5 \%$ by 6 months). Blood groups $\mathrm{B}(10 \%)$ and $\mathrm{AB}(15 \%)$ both had increased numbers of patients who were delisted because of clinical deterioration after 6 months of waiting, which was probably affected by the relative smaller sample size and the rarity of these blood groups in the Canadian population. The cardiac diagnosis also differed among patients who were delisted for clinical deterioration, with $5 \%$ in the HLHS group and $10 \%$ in the complex CHD group.

\section{Delisting for Clinical Improvement or Surgical Intervention}

Of the patients who were listed as Canadian status 4, $10 \%$ were eventually delisted because of clinical improvement. Fifteen percent of patients with HLHS were delisted because of clinical improvement or were offered another surgical intervention by 6 months after listing, compared 
TABLE 2. Patient characteristics at time of listing $(N=308)$

\begin{tabular}{|c|c|}
\hline \multicolumn{2}{|l|}{ Demographics and clinical features } \\
\hline Male sex & $140(45 \%)$ \\
\hline Age at listing (y, median and range) & $1.6(0.0-17.9)$ \\
\hline Fetal listing & $25(8 \%)$ \\
\hline \multicolumn{2}{|l|}{ Diagnosis } \\
\hline HLHS & $73(24 \%)$ \\
\hline Complex CHD other than HLHS & $106(34 \%)$ \\
\hline Dilated cardiomyopathy & $73(24 \%)$ \\
\hline Restrictive cardiomyopathy & $18(6 \%)$ \\
\hline Other cardiomyopathy & $11(4 \%)$ \\
\hline EFE or LV tumor & $5(1 \%)$ \\
\hline Primary graft failure & $10(3 \%)$ \\
\hline Graft vasculopathy & $12(4 \%)$ \\
\hline \multicolumn{2}{|l|}{ Blood group } \\
\hline A & $105(34 \%)$ \\
\hline $\mathrm{AB}$ & $13(4 \%)$ \\
\hline B & $41(13 \%)$ \\
\hline $\mathrm{O}$ & $149(48 \%)$ \\
\hline Rh positive $(\mathrm{N}=307)$ & $253(82 \%)$ \\
\hline Previous surgery & $113(37 \%)$ \\
\hline Listed for first transplant & $286(93 \%)$ \\
\hline Listed for second transplant & $20(6 \%)$ \\
\hline Listed for third transplant & $2(1 \%)$ \\
\hline \multicolumn{2}{|l|}{ Transplant listing } \\
\hline Available for $\mathrm{ABO}$-incompatible transplant & $121(39 \%)$ \\
\hline \multicolumn{2}{|l|}{ Status at listing $(N=306)$} \\
\hline 1 & $71(23 \%)$ \\
\hline 2 & $35(11 \%)$ \\
\hline $3 \mathrm{~A}$ & $78(25 \%)$ \\
\hline 3B & $7(2 \%)$ \\
\hline 4 & $115(38 \%)$ \\
\hline \multicolumn{2}{|l|}{ Status at outcome $(\mathrm{N}=306)$} \\
\hline 1 & $67(22 \%)$ \\
\hline 2 & $24(8 \%)$ \\
\hline $3 \mathrm{~A}$ & $69(22 \%)$ \\
\hline $3 \mathrm{~B}$ & $9(3 \%)$ \\
\hline 4 & $137(45 \%)$ \\
\hline Status worsened on list $(\mathrm{N}=306)$ & $39(13 \%)$ \\
\hline ECMO or VAD & $59(19 \%)$ \\
\hline \multicolumn{2}{|l|}{ Outcomes } \\
\hline Transplant & $216(70 \%)$ \\
\hline Death & $40(13 \%)$ \\
\hline Delisted because of clinical deterioration & $21(7 \%)$ \\
\hline Condition improved or surgical option & $29(9 \%)$ \\
\hline $\begin{array}{l}\text { Median time from listing to any outcome } \\
\text { (d, median and range })\end{array}$ & $29(1-930)$ \\
\hline \multicolumn{2}{|c|}{ Time to outcome (d, median and 5th-95th percentile) } \\
\hline Transplanted & $37.5(2.0-413)$ \\
\hline Death & $13.5(1-102.5)$ \\
\hline Delisted because of clinical deterioration & $10.0(3-140)$ \\
\hline Surgical intervention & $32.0(3-185)$ \\
\hline Clinical improvement & $20.0(6-312)$ \\
\hline
\end{tabular}

Data represent numbers and percentages of patients unless otherwise marked. $H L H S$, Hypoplastic left heart syndrome; $C H D$, congenital heart disease; $E F E$, endocardial fibroelastosis; $L V$, left ventricular; $E C M O$, extracorporeal membrane oxygenation; $V A D$, ventricular assist device.

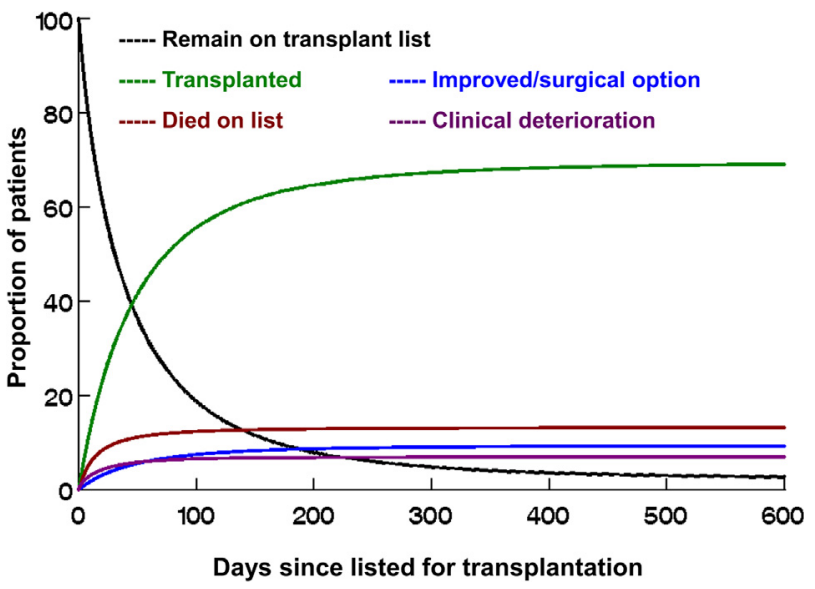

FIGURE 1. Competing risks for outcomes after listing for heart transplant. Patients can transition to any of the 4 outcomes after listing.

with $8 \%$ with complex CHD. There were 12 children $(3.9 \%)$ who were delisted for another surgical intervention. Of these, 6 were infants with HLHS who were fetal listings for heart transplant, 2 were nonfetal listings with HLHS, and 4 were nonfetal listings for complex CHD other than HLHS. At the time of censoring, 3 of the patients for whom surgical intervention had been chosen were dead, 7 were alive, and 2 had been lost to follow-up.

\section{DISCUSSION}

Decision making regarding eligibility and timing of listing for heart transplant remains challenging in the pediatric patient approaching end-stage heart failure.

TABLE 3. Multivariate analysis of risks factors for outcomes after listing for heart transplant

\begin{tabular}{lcc}
\hline \multicolumn{1}{c}{ Factor } & HR $(\mathbf{9 5} \%$ CI) & $\boldsymbol{P}$ value \\
\hline Higher probability of transplant & & \\
ECMO or VAD & $2.8(1.9-4.0)$ & $<.001$ \\
Blood group A & $2.1(1.6-2.8)$ & $<.001$ \\
Listed for ABO-incompatible transplant & $1.4(1.0-1.8)$ & .03 \\
Primary graft failure & $4.4(2.0-9.7)$ & $<.001$ \\
Higher probability of death while waiting & & \\
Younger age at listing (per y) & $1.07(1.00-1.14)$ & .05 \\
Complex congenital heart disease & $2.9(1.5-5.6)$ & .003 \\
No previous surgery & $3.6(1.0-12.5)$ & .004 \\
Primary graft failure & $9.7(2.8-33.8)$ & .001 \\
Higher probability of being delisted (clinical deterioration) & \\
Younger age at listing (per y) & $1.17(1.03-1.32)$ & .01 \\
ECMO or VAD & $2.7(0.9-7.7)$ & .06 \\
Complex congenital heart disease & $2.8(1.2-6.9)$ & .02 \\
Higher probability of being delisted (improved or surgical intervention) \\
Younger age at listing (per y) & $1.13(1.02-1.25)$ & .01 \\
Fetal listing & $2.9(1.2-7.2)$ & .02 \\
\hline
\end{tabular}

$H R$, Hazard ratio; $C I$, confidence interval; ECMO, extracorporeal membrane oxygenation; $V A D$, ventricular assist device. 
Many factors have to be taken into consideration to achieve an optimal outcome after transplant. The unpredictable factor is the timing of donor organ availability, leading to the need to balance a "too early" timing of listing versus the risk of dying on the waiting list or clinical deterioration that would render a patient no longer a candidate for transplant. We strove to identify risk factors both for waiting list mortality and for delisting within the COAS, which varies from that of UNOS by its stratification of patient medical acuity.

This study highlights the largest and longest reported experience of transplant waiting list outcomes in Canada. The institutional waiting list mortality was $13 \%$ overall, compared with the $17 \%$ reported in the recent SRTR data. ${ }^{8}$ Currently in the United States, most patients listed for pediatric heart transplant are status 1A, especially younger patients. ${ }^{14}$ This differs from the COAS, in which patients listed at status 3, 3.5, or 4 could all potentially qualify as status $1 \mathrm{~A}$ in the United States. The analysis of the SRTR data by Almond and colleagues ${ }^{8}$ looked at 3098 pediatric patients listed for heart transplant from 1999 to 2006. That study outlined a dramatic range for the waiting list mortality in the UNOS status $1 \mathrm{~A}$, depending on the level of respiratory and hemodynamic support. Organ allocation goes to the patient with the greatest accrued time on the waiting list, as opposed to the one with the highest risk for death while waiting. The level of "critical illness" is a heterogenic identifier and has been associated with poorer outcomes while waiting for an organ. Almond and colleagues ${ }^{8}$ showed in their competing outcomes analysis for status $1 \mathrm{~A}$ patients that not all status IA patients were the same. Those patients on ECMO support had the worst outcomes, relative to both those requiring ventilatory support and to those with neither form of support. This suggests that there is a subgroup of patients that, although they meet criteria for status $1 \mathrm{~A}$, can afford to wait longer than others who have requirements for mechanical support. This is the crux of the difference between the COAS and UNOS: there is wider stratification of medical urgency in the COAS.

\section{Risk Factors for Waiting List Mortality}

Previous studies to date have reported risk factors for death while waiting for a transplant that include age, diagnosis, blood group, HLA sensitization, listing strategy, and medical status, especially the need for mechanical support. ${ }^{5,8,11,15,16}$ Multivariate predictors of waiting list mortality in the United States included ECMO support, mechanical ventilation, CHD, status $1 \mathrm{~A}$, need for dialysis, nonwhite ethnicity, and a glomerular filtration rate less than $50 \mathrm{~mL} / \mathrm{min} / 1.73 \mathrm{~m}^{2}{ }^{8}$ Age was not found to be statistically significant for waiting list mortality; this is contrary to our data, which showed that younger patients had elevated risks while waiting for an organ both of death and of being delisted because of clinical worsening.
In addition, we observed that complex CHD (other than HLHS) and primary graft failure were risk factors for death while waiting. With respect to blood group as a risk factor for waiting list mortality, Morrow and colleagues ${ }^{6}$ reported that patients in blood group $\mathrm{O}$ had the longest wait times and have high waiting list mortality relative to other blood groups. Our study also observed this disadvantage for blood group $\mathrm{O}$ recipients. Consideration of donor availability could not be factored into predictive models and probably varies between Canada and the United States. Thus, Canadian centers should consider younger patients, patients with complex CHD, and patients with blood group $\mathrm{O}$ for earlier listing for heart transplants. These risk factors suggest areas of further improvement in optimizing the COAS. A discussion about relisting for primary graft failure is beyond the scope of this article, but it remains a significant risk factor for death while wait-listed, and relisting remains controversial.

\section{Delisting for Clinical Deterioration or Loss of Transplant Candidacy}

The infant population in particular is at risk either for delisting because of clinical deterioration or loss of transplant candidacy or for death. ${ }^{12,16,17}$ The 2009 SRTR data show an annual death rate of 1361 per 1000 patient-years at risk for infants younger than 1 year in 2008, compared with 170 for all age groups combined (adult and pediatric). ${ }^{14}$ With the implementation of an ABO-I transplant protocol in the COAS, a decrease in the waiting list mortality for infants younger than 6 months, from $58 \%$ to $7 \%$, was observed. ${ }^{18}$ Despite this, patients with complex CHD had the highest waiting list mortality $(16 \%)$ and the highest incidence of being delisted because of clinical deterioration $(10 \%)$, with a lower incidence of delisting because of clinical improvement or surgical intervention than those with HLHS ( $8 \%$ vs $16 \%$ ). This suggests a subgroup of patients who have reached their limit for surgical repair or palliation and also risk becoming ineligible for a transplant, representing a group that should be considered for earlier listing.

\section{Delisting for Clinical Improvement or Surgical Intervention}

Our experience was comparable to the SRTR data with respect to the patients who were delisted because of a clinical improvement ( $9 \%$ vs $8 \%$ ). Our institution has historically offered fetal listing to prospective parents for fetuses with a diagnosis of complex CHD or HLHS. ${ }^{19}$ Some of those patients listed for transplant as fetuses were delisted at birth to undergo a surgical intervention, which explains this observation. ${ }^{19}$

\section{Pretransplant Diagnosis}

Patients with cardiomyopathies have better waiting list outcomes than do patients with CHD. ${ }^{4,8,20}$ In our study, 
$73 \%$ of patients with dilated cardiomyopathy and $67 \%$ with restrictive cardiomyopathy had received transplants by 6 months, compared with $59 \%$ of those with HLHS and $55 \%$ of those with complex CHD in the same period. Previously reported data from our institution (1989-1998), found a $16 \%$ waiting list mortality for patients with cardiomyopathy, compared with waiting list mortalities of $10 \%$ for dilated cardiomyopathy and $11 \%$ for restrictive cardiomyopathy in the current study. ${ }^{13}$ This apparent decrease in the waiting list mortality for patients with cardiomyopathy possibly reflects an era effect with subsequent MCS innovations in the management of pediatric heart failure. The most common cause for long-term allograft failure is $\mathrm{CAV}$, which is also the most common indication for retransplant. ${ }^{21}$ One of the clinical challenges is deciding on the optimal timing for listing for retransplant, however, as children with CAV are often completely symptom free until they have a sudden death event. Because of their relative clinical stability, $92 \%$ of children with CAV survived to transplant despite having very long wait times.

\section{Mechanical Circulatory Support}

Recent experience with MCS as bridge to transplant, showed that patients receiving ECMO had a higher risk of death while waiting but also had a shorter time to transplant than other patient groups. ${ }^{22}$ When ECMO and VAD groups were combined in this analysis, there was a higher probability of heart transplant and also a higher probability of being delisted because of clinical deterioration. Although this appears contradictory, these higher status patients are more likely to have an organ allocated sooner but also have a higher chance of a devastating event rendering them no longer a transplant candidate. With the increasing use of pediatric VADs, there is a growing body of experience, potentially impacting transplant wait times and listing algorithms. A recent review of our institutional experience with MCS as a bridge to transplant revealed a $28 \%$ waiting list mortality for patients receiving ECMO compared with $13 \%$ for those receiving VAD support, suggesting that not all forms of mechanical support should be treated the same. ${ }^{22}$

Limitations of this study include (1) the single-center, retrospective nature of the data; (2) the study period spanning 18 years, introducing a possible era effect, especially with regard to evolving management strategies for patients with end-stage heart disease including MCS; and (3) the proportion of patients with HLHS, a population that is known to have significant preoperative and postoperative morbidity and mortality. The impact of changes in listing status for patients during the waiting list period, from the time of initial listing to status at transplant, could not be determined by this study.

\section{CONCLUSIONS}

Risk factors for dying while waiting for a heart transplant or being delisted because of clinical deterioration as a child in Canada include age younger than 1 month, a diagnosis of complex CHD, blood group $\mathrm{O}$, and the use of MCS. Knowledge of these risk factors can potentially influence the timing of consideration of listing for transplant, guide decisions during the wait for a donor organ to become available, and help to change and improve organ allocation algorithms to maximize donor organ availability for future pediatric heart transplant recipients.

\section{References}

1. McDiarmid SV, Cherikh WS, Sweet SC. Preventable death: children on the transplant waiting list. Am J Transplant. 2008;8:2491-5

2. McGiffin DC, Naftel DC, Kirklin JK, Morrow WR, Towbin J, Shaddy R, et al. Predicting outcome after listing for heart transplantation in children: comparison of Kaplan-Meier and parametric competing risk analysis. Pediatric Heart Transplant Study Group. J Heart Lung Transplant. 1997;16:713-22.

3. Sable CA, Shaddy RE, Suddaby EC, Hawkins JA, Sell JE, Martin GR. Impact of prolonged waiting times of neonates awaiting heart transplantation. $J$ Perinatol. 1997; 17:481-8.

4. Rosenthal DN, Dubin AM, Chin C, Falco D, Gamberg P, Bernstein D. Outcome while awaiting heart transplantation in children: a comparison of congenital heart disease and cardiomyopathy. J Heart Lung Transplant. 2000; 19:751-5.

5. Feingold B, Bowman P, Zeevi A, Girnita AL, Quivers ES, Miller SA, et al Survival in allosensitized children after listing for cardiac transplantation. J Heart Lung Transplant. 2007;26:565-71.

6. Morrow WR, Naftel D, Chinnock R, Canter C, Boucek M, Zales V, et al. Outcome of listing for heart transplantation in infants younger than six months: predictors of death and interval to transplantation. The Pediatric Heart Transplantation Study Group. J Heart Lung Transplant. 1997;16:1255-66.

7. Everitt MD, Donaldson AE, Casper TC, Stehlik J, Hawkins JA, Tani LY, et al. Effect of ABO-incompatible listing on infant heart transplant waitlist outcomes: analysis of the United Network for Organ Sharing (UNOS) database. J Heart Lung Transplant. 2009;28:1254-60.

8. Almond CS, Thiagarajan RR, Piercey GE, Gauvreau K, Blume ED, Bastardi HJ, et al. Waiting list mortality among children listed for heart transplantation in the United States. Circulation. 2009;119:717-27.

9. Chen JM, Weinberg AD, Rose EA, Thompson SM, Mancini DM, Ellison JP, et al Multivariate analysis of factors affecting waiting time to heart transplantation. Ann Thorac Surg. 1996;61:570-5

10. Mital S, Addonizio LJ, Lamour JM, Hsu DT. Outcome of children with end-stage congenital heart disease waiting for cardiac transplantation. J Heart Lung Transplant. 2003;22:147-53.

11. Morrow WR, Frazier E, Naftel DC. Survival after listing for cardiac transplantation in children. Prog Pediatr Cardiol. 2000;11:99-105.

12. Pollock-BarZiv SM, McCrindle BW, West LJ, Manlhiot C, VanderVliet M, Dipchand AI. Competing outcomes after neonatal and infant wait-listing for heart transplantation. J Heart Lung Transplant. 2007;26:980-5.

13. Nield LE, McCrindle BW, Bohn DJ, West LJ, Coles JG, Freedom RM, et al. Outcomes for children with cardiomyopathy awaiting transplantation. Cardiol Young. 2000;10:358-66

14. Johnson MR, Meyer KH, Haft J, Kinder D, Webber SA, Dyke DB Heart transplantation in the United States, 1999-2008. Am J Transplant. 2010 Apr;10(4 Pt 2):1035-46.

15. Dipchand AI, Naftel DC, Feingold B, Spicer R, Yung D, Kaufman B, et al. Outcomes of children with cardiomyopathy listed for transplant: a multi-institutional study. J Heart Lung Transplant. 2009;28:1312-21.

16. Mah D, Singh TP, Thiagarajan RR, Gauvreau K, Piercey GE, Blume ED, et al Incidence and risk factors for mortality in infants awaiting heart transplantation in the USA. J Heart Lung Transplant. 2009;28:1292-8.

17. Chrisant MR, Naftel DC, Drummond-Webb J, Chinnock R, Canter CE, Boucek MM, et al. Fate of infants with hypoplastic left heart syndrome listed for cardiac transplantation: a multicenter study. J Heart Lung Transplant. $2005 ; 24: 576-82$ 
18. West LJ, Karamlou T, Dipchand AI, Pollock-BarZiv SM, Coles JG, McCrindle BW. Impact on outcomes after listing and transplantation, of a strategy to accept $\mathrm{ABO}$ blood group-incompatible donor hearts for neonates and infants. J Thorac Cardiovasc Surg. 2006;131:455-61.

19. Pollock-BarZiv SM, McCrindle BW, West LJ, Dipchand AI. Waiting before birth: outcomes after fetal listing for heart transplantation. Am J Transplant. 2008;8:412-8.
20. Conway J, Dipchand AI. Transplantation and pediatric cardiomyopathies: indications for listing and risk factors for death while waiting. Prog Pediatr Cardiol. 2011;32:51-4.

21. Aranda JM Jr, Hill J. Cardiac transplant vasculopathy. Chest. 2000;118:1792-800

22. Jeewa A, Manlhiot C, McCrindle BW, Van Arsdell G, Humpl T, Dipchand AI. Outcomes with ventricular assist device versus extracorporeal membrane oxygenation as a bridge to pediatric heart transplantation. Artif Organs. 2010;34:1087-91. 